\title{
Direitos fundamentais e controle judicial
}

\author{
Fundamental rights and judicial review
}

\author{
Estefânia Maria de Queiroz Barboza* \\ Thierry Chozem Zamboni Kotinda*
}

\section{Resumo}

O presente artigo instiga o estudo acerca dos fundamentos legitimadores do controle judicial de políticas públicas, visto a partir do surgimento dos direitos fundamentais, do Estado de Direito, com os fundamentos liberais para o controle da administração pública e, especialmente, os limites do controle externo realizado pelo Poder Judiciário, bem como sobre a pretensa constitucionalização do controle judicial de políticas públicas, entendida como a superação da ideologia liberal acerca do papel do Poder Judiciário na efetivação dos direitos fundamentais. Analisa-se, em segundo plano, a necessidade de se repensar a lógica normativa escrita por Montesquieu acerca da separação dos Poderes, objetivando-se ampliar a efetividade dos direitos fundamentais.

Palavras-chave: Direitos fundamentais. Controle judicial de políticas públicas. Constitucionalização judiciária.

\section{Abstract}

This article instigate the study of the legitimizing bases of judicial review of public policies, seen from the emergence of Fundamental Rights, of rule of law - with the liberal foundations for the control of public administration and especially the limits of external control performed by the judiciary - as well as the alleged constitutionalism of judicial review of public policies, understood

* Professora do Departamento de Direito Público da UFPR. Professora de Direito Constitucional do PPGD da UniBrasil e da Graduação da Universidade Positivo. Menção Honrosa Prêmio Capes de Tese 2012. Visiting Researcher na Osgoode Hall Law School 2008/2009. Curitiba - Paraná Brasil. Email: estefaniaqueiroz@uol.com.br

** Assessor jurídico no Tribunal de Justiça do Estado do Paraná. Mestrando em Direitos Fundamentais e Democracia nas Faculdades Integradas do Brasil - UniBrasil. Pesquisador associado ao Conselho Nacional de Pesquisa e Pós-Graduação em Direito. Curitiba - Paraná Brasil. Email: thierryczk@gmail.com 
as the overcoming of the liberal ideology about the role of the judiciary in the enforcement of fundamental rights. It is analyzed in the background, the need to rethink logic normative written by Montesquieu about the separation of powers, aiming to expand the effectiveness of fundamental rights.

Keywords: Fundamental rights. Judicial control of public policy. Judicial constitutionalism.

\section{Introdução}

O núcleo das Constituições modernas (BARROSO, 2009; PUCCINELLI JÚNIOR, 2007; FACHIN, 2009; PÉREZ LUÑO, 2004) é formado, essencialmente, pelos direitos fundamentais ${ }^{1}$, concebendo diversas condições materiais e imateriais (FLORES, 2009) de direitos que persuadem a concretização do princípio da dignidade da pessoa humana, seja através da acessão de liberdades e garantias, seja através de prestações positivas (SCHIER, 2009) intermediadas pela administração pública ou por quem lhe faça as vezes.

$E$ os direitos fundamentais, não importando a geração em que se classificam (OLIVEIRA, 2007), são impulsionados pelo Estado (BARBOZA, 2007) através de diversos programas e ações governamentais, com o propósito de efetivar essas liberdades e garantias fundamentais estabelecidas na ordem jurídica. No entanto, tal promoção não depende da iusfundamentalidade da norma, posto que todos os direitos fundamentais são, em alguma dimensão, positivos "e, portanto, demandam algum tipo de prestação pública [...] para sua efetivação" (GALDINO, [2000?], p. 200). Por certo, os direitos de prestações

\footnotetext{
"Ser um direito fundamental significa, em Estado constitucional de Direito, ter uma importância, dignidade e força constitucionalmente reconhecidas que, no domínio das relações gerais entre o Estado e o indivíduo, elevam o bem, a posição ou a situação por ele tutelada à qualidade de limite jurídico-constitucional à atuação dos poderes públicos. Significa, por outro lado, já no plano das relações entre os poderes públicos, que os bens, posições ou situações tuteladas pelos direitos fundamentais são retirados da plena disponibilidade decisória do poder político democrático, sendo a sua garantia atribuída, em última análise, ao poder judicial, designadamente à justiça constitucional." (NOVAIS, 2010, p.251).
} 
negativas demandam, indiretamente, custos para a efetivação, ao contrário dos direitos de prestação positiva (MÂNICA, 2008).

Não obstante, um dos grandes argumentos contrários à realização dos direitos sociais de cunho prestacional é que estes necessitam de disponibilidade de recursos por parte do Estado, enquanto os direitos civis e políticos, em face de seu caráter negativo, independeriam de qualquer atuação do Estado.

Piovesan (2003, p. 245) rebate a questão do custo como óbice para a realização dos direitos fundamentais sociais ressaltando "que tanto os direitos sociais, como os direitos civis e políticos demandam do Estado prestações positivas e negativas"; por conseguinte, a implementação dos direitos civis e políticos também demandam um custo alto do aparato estatal e nem por isso deixam de ser realizados.

Holmes e Sunstein (apud AMARAL, 2001, p. 73-74) demonstram que "todos os direitos têm custos porque todos pressupõem o custeio de uma estrutura de fiscalização para implementá-los" e fazem um breve relato do custo dos direitos, tidos como negativos ou de liberdade nos Estados Unidos:

A Consumer Product Safety Commission gastou em 1996 41 milhões de dólares analisando e identificando produtos potencialmente danosos e fiscalizando o cumprimento dos padrões de segurança. Já o Departamento de Justiça dos Estados Unidos, no mesmo ano, gastou US\$ 64 milhões em 'questões de direitos civis'. A Occupational Safety and Health Administration (OSHA) consumiu US\$ 306 milhões no mesmo ano obrigando os empregadores a prover locais de trabalho mais seguros e saudáveis, enquanto que a Equal Employment Opportunity Comission (EEOC) despendeu US\$233 milhões para cuidar que os empregadores não discriminem na contratação, demissão, promoção e transferências. Mesmo o direito de propriedade tem custos. As leis protegem os direitos do proprietário não deixando-os abandonados à própria sorte, mas excluindo os não proprietários que, de outro modo, poderiam ficar tentados a invadir. 
Resta claro que o argumento da reserva do possível não pode prevalecer como um óbice à concretização dos direitos fundamentais sociais de cunho prestacional, inclusive quando demandam políticas públicas para sua realização, pois a garantia dos direitos individuais de liberdade ou de cunho negativo também gera alto custo ao Estado para que sejam protegidos e garantidos. ${ }^{2}$ Cabe aqui, igualmente, transcrição de trecho da obra de Sunstein e Holmes (2000, p. 52-53):

Some constitutional rights depend for their existence on positive acts by the state, and the government is therefore under a constitutional duty to perform, not to forbear, under the Constitution as it stands. If it allows one person to enslave another, by doing nothing to disrupt an arrangement that amounts to involuntary servitude, the state has violated the Thirteenth Amendment. Under the First Amendment's protection of freedom of speech, states must keep streets and parks open for expressive activity, even though it is expensive to do this, and to do it requires an affirmative act. Under the protection against 'takings' of private property without just compensation, the government is probably under an obligation to create trespass law and to make it available to property owners, and a partial or complete repeal of the law of trespass - a failure to act, in other words, to protect private property - would likely b unconstitutional. If a judge accepts a bribe offered by a defendant and therefore does nothing to protect the plaintiff's rights, the judge has violated the due process clause. If a state declines to make its courts available to enforce certain contract rights, it has probably impaired the obligations of contracts, in violation of the contracts clause. In all these cases, the government is obliged, by the Constitution to protect and to perform. Practically speaking, the government 'enfranchises' citizens by providing the legal facilities, such as polling stations, without which they could not exercise their rights. The right

2 Em sentido contrário: "A questão da escassez se põe de maneira especial no acesso à saúde. Algumas pessoas podem pensar que quando a saúde e a vida estão em jogo, qualquer referência a custo é repugnante, ou até imoral. Mas o aumento do custo com tratamento tornou essa posição insustentável." (AARON; SCHWARTZ apud AMARAL, 2001, p. 136). 
to vote is meaningless if polling place officials fail to show up for work. The right to just compensation for confiscated property is a mockery if the Treasury fails to disburse. The First Amendment right to petition for a redress of grievances is a right of access to government institutions and a right, incidentally, that assumes that the government can perform for the benefit of aggrieved citizens. Nor is this all. ${ }^{3}$

Sunstein (2004) afirma categoricamente que não existem direitos negativos, pois mesmo o direito de propriedade ou de liberdade de expressão precisa de garantia positiva do Estado, não havendo, portanto, por que ser contra a aplicação dos direitos sociais, uma vez que envolvem uma atuação positiva do Estado e, portanto, maior custo, afinal, todos os direitos, para serem garantidos, custam dinheiro.

Além das questões levantadas, o princípio da "reserva do possível" funciona também como um óbice à legitimação do Judiciário na realização dos direitos fundamentais sociais, negando alguns autores "de maneira categórica a competência dos juízes ('não legitimados pelo voto') a dispor sobre medidas de políticas sociais que exigem gastos

\footnotetext{
"Alguns direitos constitucionais dependem, para sua existência, de condutas estatais positivas. Portanto o Estado está sob um dever constitucional de agir, não de abster-se. Se deixar uma pessoa escravizar outra, nada fazendo para desfazer a situação que configura servidão involuntária, o Estado terá violado a Décima-terceira Emenda. Por força da proteção dada pela Primeira Emenda à liberdade de expressão, o Estado está obrigado a manter ruas e parques abertos para manifestações, muito embora isso seja caro e requeira uma conduta positiva. Por força da proteção constitucional contra a 'privação' da propriedade privada sem justa compensação, o Governo está provavelmente obrigado a criar leis contra os esbulhos e invasões, bem como tornar tais garantias acessíveis aos proprietários privados - uma falha em agir, uma falha em proteger a propriedade privada, pareceria inconstitucional. Se um juiz aceitar propina oferecida pelo réu e assim nada fizer para proteger os direitos do autor, tal juiz terá violado a garantia do devido processo. Se o Estado não tornar seus tribunais acessíveis para garantir a eficácia de garantias contratuais, ele terá provavelmente arruinado as obrigações contratuais, violando a garantia constitucional dos contratos. Em todos esses casos, o Governo está obrigado, pela Constituição, a proteger e a agir. Em termos práticos, o Governo 'concede direitos civis' aos cidadãos, provendo aparatos legais, como zonas eleitorais, sem os quais não seria possível exercer tais direitos. O direito de voto não tem sentido se mesários, presidente de mesa e escrutinadores não comparecessem. O direito a uma justa compensação pela propriedade confiscada é uma piada se o Tesouro não efetuar o pagamento. O direito de petição para ver reparado um dano, assegurado pela Primeira Emenda, é o direito de acesso a instituições governamentais e o direito, eventual, de ser indenizado." (HOLME; SUNSTEIN, 2000, p. 52-53).
} 
orçamentários" (KRELL, 2002, p. 52). Ou seja, quando se trata da realização dos direitos fundamentais sociais pelo Judiciário, este tem questionada sua legitimidade democrática, pois "a concretização de direitos sociais implicaria a tomada de opções políticas em cenários de escassez de recursos" (SOUZA NETO, 2003, p. 44), levando à conclusão de que a tomada de políticas públicas não poderia ser feita por um Poder não eleito, mas tão somente pelo Executivo e Legislativo, os quais, por sua vez, refletiriam a vontade da maioria.

Por outro lado, os programas e ações governamentais que buscam a efetivação dos direitos sociais estão incorporados no âmbito da discricionariedade dos agentes políticos, por conseguinte, são atos de governo tipicamente decorrentes dos Poderes Executivo, no exercício de sua atividade administrativa (TAMER, 2005), e Legislativo, por meio das Leis Orçamentárias (HOLMES; SUNSTEIN, 2000), recebendo a denominação de políticas públicas.

$\mathrm{Na}$ verdade, defende-se que a discricionariedade consista apenas no modo de executar as políticas públicas, mas não há discricionariedade em não realizar uma política pública necessária à realização de um direito fundamental, sob pena de uma omissão inconstitucional. Nesse caso, o Judiciário teria legitimidade para exigir que o poder político apresentasse a política pública, mas seria discricionário o modo de realizá-la.

Antes de entrar propriamente no tema do controle judicial de políticas públicas, é mister analisar o conceito de políticas públicas.

Dworkin (2002, p. 148) é um dos poucos juristas que tenta definir o que são questões políticas, diferenciando-as de princípios, cabendo aos Tribunais apenas decisões baseadas nestes:

Los argumentos políticos justifican una decisión política demostrando que favorece o protege alguna meta colectiva de la comunidad en cuanto todo. El argumento en favor de un subsidio para los fabricantes de aviones, que afirma que con él se protegerá la defensa nacional, es un argumento político. Los argumentos de principio justifican una decisión 
política demostrando que tal decisión respeta o asegura algún derecho, individual o del grupo. El argumento a favor de las leyes que se oponen a la discriminación (racial en los Estados Unidos), y que sostiene que una minoría tiene derecho a igual consideración y respeto, es un argumento de principio.

Dessa definição, pode-se deduzir que o conceito de política pública diz respeito a metas coletivas e objetivos sociais que demandam programas de ação pelos poderes públicos, comuns num Estado que se pretende social. Já os princípios estariam mais relacionados a proteções de direitos individuais.

Em sentido distinto, Comparato (1998, p. 44) afirma que política "não é uma norma nem um ato, ou seja, ela se distingue nitidamente dos elementos da realidade jurídica, sobre os quais os juristas desenvolveram a maior parte de suas reflexões, desde os primórdios da iurisprudentia romana".

Para Bucci (2006, p. 39):

Política pública é o programa de ação governamental que resulta de um processo ou conjunto de processos juridicamente regulados visando coordenar os meios à disposição do Estado e as atividades privadas, para a realização de objetivos socialmente relevantes e politicamente determinados.

Já de acordo com Mancuso (2001, p. 730-731), política pública pode ser considerada

conduta comissiva ou omissiva da Administração Pública, em sentido largo, voltada à consecução de programa ou meta previstos em norma constitucional ou legal, sujeitando-se ao controle jurisdicional amplo e exauriente, especialmente no tocante a eficiência dos meios empregados e a avaliação dos resultados alcançados.

As políticas públicas envolvem um estudo complexo e multidisciplinar. No campo jurídico, o tema é usualmente relacionado ao 
estudo da Ciência Política (SANTOS, 2003), do Direito Constitucional, do Direito Financeiro e, principalmente, do Direito Administrativo (BUCCI, 1997), posto que esta última é a disciplina jurídica que ampara a atividade da administração pública, com o propósito de conservá-la vinculada ao princípio da legalidade, bem como examina a atuação do Estado em consonância com o seu regime jurídico típico, formado a partir de um binômio de prerrogativas e sujeições que derivam dos princípios fundamentais dessa disciplina: o princípio da supremacia do interesse público sobre o privado e o princípio da indisponibilidade do interesse público pela administração (BANDEIRA DE MELLO, 2009).

Outrossim, conscientes de que o discurso jurídico sobre a efetividade dos direitos fundamentais positivos (SARLET, 2007) colide na "impossível" tarefa do Estado de suscitar toda essa "inflação legislativa" (MASSA-ARZABE, 2006) prevista na Constituição da República de 1988, encontramos, atualmente, a expansão do ativismo judiciário empenhado na proteção da dignidade da pessoa humana como nunca antes visto (CLÈVE, 2008).

Desse modo, para o melhor entendimento acerca do controle judicial de políticas públicas, devemos pensar a origem do exercício do controle da administração pública.

\section{A revisão judicial liberal do Estado}

Se as Constituições anteriores tinham como características o conjunto de normas que demarcavam cogentemente a estrutura e organização política do Estado, suas formas de atuação e as limitações do Poder Público, a restrição da atuação estatal sempre esteve atrelada de modo consequente à legalidade do Codex institucional e à legalidade estrita, estando restrita ao ideário liberal-emancipador.

O princípio da legalidade que se manifesta com as Cartas liberais do Estado moderno como fundamento jurídico essencial para a uniformização do poder estatal e da vida pública suscitou a crença de plenitude da lei democrática do Parlamento representativo 
(COMPARATO, 2003). Consequentemente, redundou na limitação da atividade judiciária à simples aplicação das normas provenientes do anseio popular, teoricamente pleno e imparcial para a regulação da vida em sociedade (FIORAVANTI, 2000).

Isso porque o princípio da legalidade modelou o Estado de direito a uma ideologia de legalidade voltada para a aplicação de regras jurídicas positivadas e separação dos Poderes (POZZOLO, 2006).

Não obstante o princípio da legalidade possa ser considerado fundamento central do exercício de controle e revisão dos atos da administração pública, ele "só experimenta significado na interação com os demais princípios fundamentais”, como destaca Freitas (2009, p. 72).

Por conseguinte, se o princípio da legalidade, àquela época, não acompanhava outros valores sociais, o controle da administração pública, prevista no artigo 15 da Declaração Universal dos Direitos do Homem e do Cidadão de 1789, em tempo algum se afastou da análise da proteção dos valores liberais de reconhecimento.

A legalidade codificada das primeiras Constituições, indubitavelmente, experimentou um significado no exercício do controle e revisão das funções administrativas, visto que sinalou institucionalmente os objetivos ideológicos do Estado nacional e estabeleceu os limites de sua atuação na vida privada dos seus administrados.

\section{A constitucionalização do controle judicial de políticas públicas}

Devido ao fato de uma das principais funções da Constituição da República estar atrelada à proteção dos direitos fundamentais, restringindo e racionalizando o exercício do poder, estuda-se o princípio republicano vinculado à teoria da separação dos Poderes, limitando o poder estatal através da teoria da repartição orgânica, também conhecida como separação horizontal de poder (MELO, 2007). 
Ela está vinculada à limitação dos Poderes do Estado para proteger e aprimorar a concretização dos direitos fundamentais, de tal maneira que o surgimento e a positivação da teoria da separação dos Poderes ocorreram com a formação do Estado moderno e a Declaração de 1789, passando a direcionar a racionalidade jurídica.

Entretanto, a existência de diversos Poderes não surgiu no Estado moderno (WOOD, 2011). Sabe-se que, na Antiguidade, vários filósofos já revelavam a existência de diversas funções públicas ou funções do Estado (NATEL, 2007). Mas é na modernidade, através do ideário de Montesquieu, que essa teoria adquire a formatação hodierna. Seu trabalho foi além da mera comprovação da existência de vários Poderes (MONTESQUIEU, 1748 apud COUTO, 2004) e verificou que, em todas as experiências institucionais de autoritarismo, essas várias funções estavam centralizadas nas mãos de uma única pessoa ou organização.

Diante disso, as diversas funções do Estado deveriam ser desempenhadas por autoridades diferentes. Portanto, de acordo com cada função, deveria existir uma autoridade diversa para o seu desempenho.

Tal teoria sofreu modulações específicas para cada experiência nacional. Na França, a separação dos Poderes foi aplicada com um direcionamento mais rígido. Já em outros países, foi assumido o modelo desenvolvido nos Estados Unidos, fundado na existência de controles recíprocos entre os vários poderes. A ideia de uma forte fragmentação do poder nos Estados Unidos se dá a partir dos ideais federalistas. Primeiro, pensa-se numa limitação horizontal do Poder, instituindo-se não só a separação de Poderes estabelecida por Montesquieu (2004), mas também desenvolvendo esse princípio para a ideia de "checks and balances".

O "checks and balances" (pesos e contrapesos) traz uma ideia de controles recíprocos entre os Poderes. Para os federalistas, não seria possível admitir o princípio da separação rígida entre os Poderes, permitindo-se que eles fossem absolutos, sem qualquer controle. A interpretação dos federalistas acerca da teoria de Montesquieu (2004) 
era que, se qualquer um dos Poderes ficasse sem controle, poder-se-ia cometer abusos e arbitrariedades ${ }^{4}$.

Nesse viés, antes da decisão paradigmática de Marshall, no caso Marbury v. Madison, os federalistas desenvolveram a teoria da separação dos Poderes a partir da ideia de controles recíprocos entre eles, num contexto totalmente diverso do que ocorreu na França, especialmente no que diz respeito à relação entre Judiciário e Legislativo (HAMILTON; JAY; MADISON).

Se na França havia uma grande preocupação em limitar-se o Poder Judiciário no contexto pós-Revolução Francesa, tendo em vista seu passado comprometido com a nobreza e os ideais absolutistas, nos Estados Unidos, a desconfiança não se dava em relação ao Judiciário, mas ao Parlamento.

Enquanto para o rei inglês todos os súditos estavam representados no Parlamento, tal raciocínio não se coadunava com o dos colonos americanos. A proximidade entre os representados e a população da América tornava estranha e irreconhecível a autoridade de um Parlamento distante, não eleito e não conhecido. Enquanto a Revolução Francesa se opõe ao mandato imperativo e tende à eleição dos representantes, a americana desconfia destes (FIORAVANTI, 2000).

4 "My second thesis has been that this judicial role is a legitimate one. Surely we might disagree with, even fight against, certain determinations or trends in constitutional adjudication. Still, a century and a half of Continental history is there to demonstrate that the alternative solution is worse indeed. In the absence of judicial control, the political power is more easily exposed to the risk of perversion. Judicial control, of course, is no infallible remedy/ as a bulwark of our freedoms, it might often prove to be too weak to resist tyranny, as the experience of many countries demonstrates. If not an invincible bulwark, however, it may at least act as a warning and a restraint." "Minha segunda tese tem sido a de que este papel judicial é legítimo. Certamente podemos discordar ou até lutar contra certas determinações ou tendências contidas em decisões no âmbito constitucional. Ainda assim, um século e meio de história continental está aí para demonstrar que as soluções alternativas são, de fato, piores. Na ausência de controle judicial, o poder político fica mais facilmente exposto ao risco de perversão. O controle judicial, é claro, não é um remédio infalível, tal qual uma fortaleza que protege as nossas liberdades; ele pode até frequentemente se mostrar fraco demais para resistir à tirania, como a experiência de muitos países demonstra. Se não se trata de uma fortaleza intransponível, no entanto, ele pode ao menos agir como um aviso e como um obstáculo." (CAPPELLETTI, 1985, p. 12). 
No Federalista $n^{\circ} 48$, defende-se que a relação entre o Legislativo e o povo, por ser muito próxima, pode ser mais propensa a cometer abusos. Mas se imagina que qualquer um dos Poderes que fique sem controle e ilimitado também poderá cometer arbitrariedades (MADISON, 1788).

Dessa forma, caberá ao Judiciário, por suas funções de intérprete da lei, interpretá-la quando ela violar a Constituição, por se tratar de simples colisão entre a lei ordinária e a Lei Maior. Deve o Judiciário, nesses casos, dar prevalência à Constituição, uma vez que esta representa a verdadeira vontade do povo, enquanto a lei representaria apenas a vontade dos representantes do povo. Portanto, no caso de colisão de uma lei com a Constituição, deve esta prevalecer, sob pena de não existir um sistema constitucional.

Concebendo que na República brasileira é adotada a lógica de distribuição funcional dos Poderes nos parâmetros estadunidenses, para o estudo sobre a compleição judicial de políticas públicas, resta saber quais os limites de atuação do Poder Judiciário ou os obstáculos à sua atuação quando os demais Poderes forem chamados a submeterse à função jurisdicional.

Para fortalecer o sistema de controles recíprocos, disserta Barroso (2009, p. 173):

o conteúdo nuclear e histórico do princípio da separação dos Poderes pode ser descrito nos seguintes termos: as funções estatais devem ser divididas e atribuídas a órgãos diversos e devem existir mecanismos de controle recíproco entre eles, de modo a proteger os indivíduos contra o abuso potencial de um poder absoluto.

Para que se tenha um eficaz controle de pesos e contrapesos dos Poderes Executivo e Legislativo, é necessário um crescimento dos papéis do Poder Judiciário, sob pena de, mantendo-se o princípio da estrita separação de Poderes, haja um Judiciário "perigosamente débil e confinado, em essência, aos conflitos privados" (CAPPELLETTI ,1999, p. 53). Esse ideal de rígida separação de Poderes acabou por levar à 
"existência de um legislativo totalmente não controlado, como de um executivo também praticamente não controlado", o que, por sua vez, significou períodos de perigo na história mundial, nos quais "o poder era concentrado nas assembleias legislativas e grupos políticos que as dominavam", como ocorrido na Itália pré-fascista ou na Alemanha de Weimar.

De acordo com Appio (2005, p. 135), "a avaliação judicial das políticas públicas não se apresenta como novidade no contexto brasileiro, já que se faz a partir do controle de legalidade e legitimidade dos atos administrativos".

Tal afirmação nos indica a teoria tradicional da separação dos Poderes, segundo a qual a discricionariedade ${ }^{5}$ do ato administrativo em tempo algum poderia ser objeto de controle judicial (PEREIRA JÚNIOR, 2006), haja vista que ela é um elemento típico do Poder Executivo e não admite a ingerência entre Poderes (TAMER, 2005).

Conforme explana Krell (2002, p. 87), "encontramos no Brasil uma resistência ao controle judicial do mérito dos atos do Poder Público, aos quais se reserva um amplo espaço de atuação autônoma, discricionária, onde as decisões do órgão ou agente público são insindicáveis quanto à sua conveniência e oportunidade". Por certo, os limites instituídos à revisão judicial eram os limites da estrita legalidade, devido à interpretação absoluta que se fazia da separação dos Poderes. Todavia, com os novos valores jurídicos trazidos pela Constituição da República de 1988, o Poder Judiciário assume uma "função política de controle dos atos do Poder Legislativo e Executivo" (APPIO, 2005, p. 66), ampliandose o campo de submissão judicial para a análise sobre "a legitimidade, a economicidade, a razoabilidade, a proporcionalidade, a eficiência, os resultados" (PEREIRA JÚNIOR, 2006, p. 48).

5 Conforme defende Bandeira de Mello (1993, p. 48), "discricionariedade, portanto, é a margem de liberdade que remanesça ao administrador para eleger, segundo critérios consistentes de razoabilidade, um, dentre pelo menos dois comportamentos cabíveis, perante cada caso concreto, a fim de cumprir o dever de adotar a solução mais adequada à satisfação da finalidade legal, quando, por força da fluidez das expressões da lei ou da liberdade conferida no mandamento, dela não se possa extrair objetivamente, uma solução unívoca para a situação vertente". 
Levando-se em conta que a Constituição limita e racionaliza o exercício dos Poderes para proteger os direitos fundamentais, seria "um arrematado absurdo apontar o princípio da separação dos Poderes como entrave à efetivação dos direitos fundamentais" (FREIRE JÚNIOR, 2005, p. 38), positivos ou não na Constituição (NOVAIS, 2006).

A propósito, sobre essa nova visão acerca do princípio da separação dos Poderes, Krell (2002, p. 90) destaca que "na medida em que as leis deixam de ser vistas como programas condicionais e assumem uma forma de programas finalísticos, o esquema clássico de divisão dos poderes perde sua atualidade". Cappelletti (1999, p. 53) sustenta que, nas experiências radicais, "o ideal da estrita separação dos Poderes teve como conseqüência um Judiciário perigosamente débil, e confinado, em essência, aos conflitos 'privados'”, ou seja, quando o princípio da separação dos Poderes foi interpretado de modo extremo, o Judiciário se evidenciou por ser um órgão limitado a dirimir contendas de ordem privada, implicando num Estado em que os cidadãos padecem de limitações no que diz respeito à efetivação dos direitos fundamentais.

Deve-se salientar que a intervenção judicial no exercício do controle de políticas públicas (PRADO, 2007) não evidencia nenhuma ameaça à sobrevivência da democracia. Defende Barboza (2007, p. 191): "Quando a inércia dos Poderes Executivo e Legislativo configurar um óbice ao regular funcionamento da democracia, é legítimo ao Judiciário atuar na efetivação dos direitos fundamentais sociais, justamente para permitir a manutenção do processo democrático".

A respeito das funções jurisdicionais e da legitimidade do Poder Judiciário para realizar as determinações constitucionais, Finger (2003, p. 153-154) defende:

Com efeito, ninguém discute a competência do Poder Legislativo para legislar sobre os direitos sociais; de igual modo, ninguém discute a competência do Poder Executivo para realizar ações administrativas para a prestação dos direitos sociais. No entanto, não é da competência de nenhum desses poderes decidir se garantirão ou não tais direitos, porque isto é uma determinação constitucional. 
Assim, sendo um órgão criado para concretizar os fins constitucionais, o Poder Judiciário está tão vinculado à Lei Fundamental quanto os demais poderes, gozando, portanto, de legitimidade para materializar tais direitos.

No mesmo sentido, Hirschl (2004) alega que a democracia não pode ser erigida em um ambiente no qual as minorias não tenham proteções legais contra os abusos políticos que as maiorias podem constituir no exercício do poder político.

No entanto, quanto à formulação e execução de políticas públicas, essa hipotética intromissão do Poder Judiciário lança uma nova perspectiva sobre os institutos representativos, posto que membros do quadro Judiciário restringem parte da discricionariedade dos representantes escolhidos através de um processo eleitoral popular.

Deve-se ressaltar que a atividade judicial não possui a prerrogativa de dispor de políticas públicas, em substituição aos Poderes Executivo e Legislativo. Não obstante, toda vez que for provocado e houver o reconhecimento da ineficiência da administração pública em garantir direitos constitucionais ou constitucionalmente fundamentais, caberá ao juiz asseverar a realização do interesse público.

Pode-se, inclusive, adotar o exemplo da Corte Constitucional da África do Sul, no sentido de que, apesar de ser efetivamente um problema de política pública a alocação de recursos para determinados projetos que buscam a implementação de direitos sociais, isso não significa dizer que o Judiciário não tenha nenhum papel na realização desses direitos. Veja-se, por exemplo, o direito à saúde e à educação. Eles possuem perspectivas que permitem sua adequada realização, razão pela qual "a prestação concreta de serviços públicos precários e insuficientes, por parte dos municípios, dos estados e da União, deveria ser compelida e corrigida por parte dos tribunais" (KRELL, 2002, p. 56).

Sunstein (2004) traz a experiência de duas decisões da Corte Constitucional Sul-Africana a respeito da posição tomada pelo Judiciário na realização dos direitos fundamentais sociais, demonstrando que, 


\section{mesmo com recursos escassos, é possível a maximização desses direitos:}

The constitutional Court of South Africa has issued two important opinions involving social and economic rights. The first of these involved the right to shelter; the second, the right to health care. In both decisions, the Constitutional Court concluded that courts could and should protect social and economic rights. And in both, the court ruled that the nation's government had failed to comply with its constitutional obligations. In Government of the Republic of South Africa v. Grootboom, the court said that the government was required to come up with a a program of emergency housing for those in need of it. In Minister of Health v. Treatment Action Campaign, it ruled that the government was required to allow HIV-positive citizens access to drugs that promised to help them. The court did not say that every person in South Africa had an individual right to decent shelter or appropriate health care. But it did say that the government is under an obligation to take the two rights seriously and adopt programs that attempt to ensure them. [...] They suggest that the underlying rights can serve, not to preempt democratic deliberation, but to ensure democratic attention to important interests that might otherwise be neglected in ordinary debate. ${ }^{6}$

6 "A Corte Constitucional da África do Sul emitiu duas importantes opiniões envolvendo direitos econômicos sociais. A primeira delas envolveu o direito a ter abrigo; a segunda, o direito a cuidado de saúde. Em ambas as decisões, a Corte Constitucional concluiu que cortes podiam e deviam proteger direitos econômicos sociais. E em ambas, a corte determinou que o governo da nação havia falhado no cumprimento das suas obrigações constitucionais. No caso 'Government of the Republic of South Africa v. Grootboom', a Corte determinou que o governo apresentasse um programa político emergencial de moradia para os setores mais necessitados da sociedade. E no caso 'Minister of Health v. Treatment Action Campaign', a Corte determinou que o governo providenciasse aos cidadãos HIV positivos o direito de ter o remédio que promete ajudá-los. A Corte não disse que cada pessoa na África do Sul tinha um direito individual a abrigo decente ou a tratamentos de saúde. Mas disse que o governo é obrigado a levar os dois direitos a sério e a adotar programas que buscam assegurá-los. [...] Sugerem que os direitos fundamentais podem servir, não para impedir uma deliberação democrática, mas ao contrário, para assegurar uma preocupação democrática com importantes interesses que podem ser negligenciados no debate ordinário." (SUNSTEIN, 2004, p. 211-212). 
Assim, a Corte Sul-Africana assumiu que o Judiciário pode e deve proteger os direitos econômicos e sociais, definindo que cabe ao Governo promover políticas para proteção desses direitos.

Por outro lado, não se pode descurar que a atividade jurisdicional, conquanto seja a atividade de resolução de conflitos, abrange igualmente, ainda mais durante o processo das demandas constitucionais, o exercício de atividades discricionárias, quer dizer, o Poder Judiciário não é simplesmente um órgão de mera decisão sobre direitos, mas de reflexões políticas (CAPPELLETTI, 1999).

A decisão judicial-normativa não se fundamenta em elementos aleatórios e facilmente controvertíveis (NOVAIS, 2006), posto que o juiz, narrador do Judiciário, embasa sua decisão de acordo com os anseios políticos e culturais da sociedade abrangida por sua jurisdição (DWORKIN, 2000), pretendendo não seja alvo de controvérsias sociais ou de críticas populares que asseverem a legitimidade da função jurisdicional em si (HIRSCHL, 2004).

Ademais, "não existe discricionariedade na omissão do cumprimento da Constituição. Na verdade, trata-se de arbitrariedade que pode e precisa ser corrigida" (FREIRE JÚNIOR, 2005, p. 71). Contudo, faz-se necessário salientar que o Judiciário atua com o animus elaborador da política pública, mas como instrumento de efetivação dos direitos fundamentais, decidindo um conflito que concernente ao interesse público.

Está expresso no artigo $5^{\circ}$, inciso XXXV, da Constituição da República que "a lei não excluirá da apreciação do Poder Judiciário lesão ou ameaça a direito" (BRASIL, 1988). Por conseguinte, "uma interpretação adequada do dispositivo leva à conclusão de que não somente lei, mas também atos, inclusive omissos, do Poder Legislativo e Executivo não podem ficar sem controle" (FREIRE JÚNIOR, 2005, p. 71).

A Constituição, quando confere ao Judiciário a guarda da Constituição, o faz intencionalmente. Se fosse outro o animus 
constituinte, teria sido explicitada na Carta Magna tal restrição. Não é o caso!

Por outra parte, não pode ser considerada novidade a função jurisdicional-concretizadora de direitos fundamentais. Segundo Kelsen (1988), quando da insuficiência normativa positivada ou consuetudinária, poderia o órgão judicial determinar, no caso concreto, as condições materiais de gozo de um direito legalmente autônomo, desde que sujeito aos princípios gerais da ordem jurídica. No mesmo sentido, Dworkin (2002, p. 127) defende:

O positivismo jurídico fornece uma teoria dos casos difíceis. Quando uma ação judicial específica não pode ser submetida a uma regra de direito clara, estabelecida de antemão por alguma instituição, o juiz tem, segundo tal teoria, o 'poder discricionário' para decidir o caso de uma maneira ou de outra. Sua opinião é redigida em uma linguagem que parece supor que uma ou outra das partes tinha o direito preexistente de ganhar a causa, mas tal idéia não passa de uma ficção. Na verdade, ele legisla novos direitos jurídicos (new legal rights), e em seguida os aplica retroativamente ao caso em questão.

A resistência a interpretações distintas referentes à separação dos Poderes ainda persiste no Brasil. Contudo, é possível verificar que nos países em que a separação é extrema, as demandas contra o Estado são julgadas por órgãos não judiciários. Isso porque não se admite que um poder possa julgar as atividades e condutas que não sejam da competência de sua organização. De tal sorte, a revisão dos atos administrativos e políticos ocorre dentro da mesma estrutura da República que lhe deu origem (BANDEIRA DE MELLO, 2009).

Todavia, o Poder Constituinte brasileiro explicita que as demandas contra o Estado, assim como o controle de constitucionalidade das leis, são efetivadas por um Poder estranho à estrutura que as concebe: o Poder Judiciário. A atividade de controle desempenhada é igual à dos outros sistemas homogêneos, porém, realizada por um órgão distinto. 
Afirma Appio (2005, p. 156), quando acusa que não é possível haver controle da formulação de políticas públicas pelo Judiciário:

a determinação de retirada de receita de uma determinada rubrica aprovada em lei ou a redestinação de verbas para as obras e serviços que o juiz reputa prioritários, culminaria por concentrar nas mãos do Judiciário as funções legislativa, executiva e judicial, convertendo-o num 'superpoder'.

Não se trata da criação de um superpoder ,como dito, mas da imputação ao Judiciário de uma atividade que é essencial ao Estado Democrático de Direito. Para Ommati (2004, p. 68):

O papel ao Judiciário, ao controlar a discricionariedade, não será, jamais, o de anular o papel da Administração - vez que aniquilaria a própria 'Separação de Poderes' essencial para a efetivação da democracia: ele complementa a atividade do Poder Executivo, indicando o que está correto à luz dos Princípios da Administração e dos princípios constitucionais, e invalidando aquilo que confronte a ordem constitucional almejada. Há, pois, uma complementação de um Poder com o outro - nunca sobre o outro - até porque, como já foi dito, a Teoria da Separação dos Poderes não pode mais ser vislumbrada com cada Poder agindo separadamente, solitariamente: mas sim em conjunto, em perfeita harmonia. Para isso, é necessário, reitera-se, que um interfira um pouco na atuação do outro para que todos atuem juntos, solidariamente - e nunca isoladamente.

Ao analisar os princípios constitucionais do Direito Administrativo brasileiro, Bandeira de Mello (2009) leciona que não há um Poder que se fundamenta na própria existência, porém, uma prerrogativa que se embasa no dever de cumprimento de uma determinada função.

Não se aspira defender a concentração de Poderes ilimitados nas mãos dos juízes, visando fazer do Judiciário um superpoder. Pode-se extrair dos preceitos de Bandeira de Mello que os ocasionais Poderes atípicos concernentes à convencional função jurisdicional $r$ outorgados aos juízes não serão uma livre concessão de prerrogativas, mas da 
obtenção de instrumentos que viabilizem a realização dos comandos constitucionais.

Seguindo esse pensamento, Habermas (2003) alega que não teria sentido a existência do controle judicial da constitucionalidade dos atos do Executivo e Legislativo se o Judiciário não possuísse meios coercitivos de realização das suas decisões ${ }^{7}$.

\section{Conclusão}

Os direitos fundamentais são, para as Constituições modernas, o guia normativo de vinculação de toda atividade estatal, seja executiva, legislativa ou judiciária.

Sendo assim, é importante repensar os antigos institutos jurídicos organizadores da República, à luz do conteúdo material dos direitos fundamentais, superando-se a lógica normativa das Constituições liberais, fundadas nos preceitos radicais acerca da lógica da separação dos Poderes, tal como formulada por Montesquieu, a fim de garantir a máxima efetividade do texto constitucional.

$\mathrm{E}$, sabendo que "a Constituição não é estática, mas dinâmica, em continuo processo de aperfeiçoamento” (FREIRE JÚNIOR, 2005, p. 69), é importante a ressalva de que as variadas funções do Estado não podem ser continuamente interpretadas com base em valores concebidos e determinados em circunstâncias pretéritas, cujos valores e ideais não mais condizem com a realidade jurídico-social que vivenciamos na contemporaneidade.

\footnotetext{
"Não obstante, a lógica da divisão dos poderes não pode ser ferida pela prática de um tribunal que não possui os meios de coerção para impor suas decisões contra uma recusa do parlamento e do governo. A concorrência do tribunal constitucional com o legislador legitimado democraticamente pode agravar-se no âmbito do controle abstrato de normas. E, para saber se uma lei decidida pelo parlamento é conforme à constituição, ou ao menos, não contradiz a configuração coerente do sistema dos direitos, esta questão é submetida a um reexame judicial". (HABERMAS, 2003, p. 299-300).
} 
Isso porque a conciliação entre a Constituição da República e a efetividade dos direitos fundamentais depende da readequação dos interpretes do Direito, em especial, dos juízes, incumbidos de garantir, subsidiariamente, a concretização dos direitos inerentes à realização da dignidade da pessoa humana (FREIRE JÚNIOR, 2005).

Conforme apontado por Hirschl (2004, p. 32), "a existência de um Judiciário independente e ativo parece ser uma condição necessária para, assim como um produto da proliferação da democracia durante a segunda metade do século XX". Sendo assim, o desenfreamento do Poder Judiciário em busca da plena concretização dos direitos fundamentais é essencial para a construção de uma sociedade mais justa e materialmente democrática.

Não é sem razão que Novais (2006), ao tratar dos direitos fundamentais como trunfos contra a maioria, afirma que o Poder Judiciário representa para as minorias, em muitos casos, um dos únicos instrumentos efetivos de proteção das ingerências do poder político - cujo acesso pelas minorias encontra-se dificultoso nos processos democráticos de eleição política - e, consequentemente, de garantia dos direitos inerentes à manutenção ou construção da dignidade inerente à condição humana.

Todavia, é importante ponderar que a superação jurisdicional da primazia da legalidade dos atos do Parlamento, inaugurada pela Constituição de 1988 (APPIO, 2005), não se destina à elevação do Judiciário ao status de um superpoder, mas de instituição de mecanismos de controle qualitativo do poder público, conforme o texto constitucional. Aliás, conforme lecionado por do Valle (2009, p. 166),

recepcionar políticas públicas como veículo juridicizado do plano de ação estatal é fortalecer uma estrutura que concilia escolhas públicas como a manifestação de governo, e a máxima abertura de controle o desafio está em viabilizar a coexistência entre a deferência às mencionadas opções administrativas e o espaço devido reservar à livre atuação de suas instâncias de avaliação, de modo que possam conviver de forma construtiva - e não concorrem, numa linha paralisante. 
Portanto, a revisão judicial de políticas públicas não deve ser vista como afronta à ordem social, mas como instrumento de participação popular nas escolhas públicas, desde que fundada nos princípios sociais esculpidos na Constituição da República de 1988, a fim de que sejam maximizadas as garantias fundamentais indisponíveis à construção de uma sociedade um pouco mais democrática.

\section{Referências}

AARON, Henry J.; SCHWARTZ, William B. The painful prescription: rationing hospital care. Washington DC: The Brookings Institution, 1984.

AMARAL, Gustavo. Direito, escassez \& escolha: em busca de critérios jurídicos para lidar com a escassez de recursos e as decisões trágicas. Rio de Janeiro: Renovar, 2001.

APPIO, Eduardo. Controle judicial das políticas públicas. Curitiba: Juruá, 2005.

BACELLAR FILHO, Romeu Felipe. Direito público $\mathbf{x}$ direito privado. Disponível em: <http://www.oab.org.br/oabeditora/users/ revista/1205503372174218181901.pdf>. Acesso em: 25 abr. 2010.

BANDEIRADE MELLO, Celso Antônio. Curso de direito administrativo. 26. ed. rev. atual. São Paulo: Malheiros, 2009.

BANDEIRA DE MELLO, Celso Antônio. Discricionariedade e controle judicial. 2. ed. São Paulo: Malheiros, 1993.

BARBOZA, Estefânia Maria de Queiroz. Jurisdição constitucional: entre o constitucionalismo e democracia. Belo Horizonte: Fórum, 2007.

BARBOZA, Estefânia Maria de Queiroz. Jurisdição constitucional, direitos fundamentais e democracia. In: CLĖVE, Clèmerson Merlin; SARLET, Ingo Wolfgang; PAGLIARINI, Alexandre Coutinho (Coord.). Direitos humanos e democracia. Rio de Janeiro: Forense, 2007. p. 277-293.

BARCELLOS, Ana Paula de. Neo constitucionalismo, direitos fundamentais e controle das políticas públicas. Disponível em: 
<http://www.mundojuridico.adv.br/cgi-bin/upload/texto853.pdf>. Acesso em: 26 fev. 2012.

BARROSO, Luís Roberto. Curso de direito constitucional contemporâneo: os conceitos fundamentais e a construção do novo modelo. São Paulo: Saraiva, 2009.

BESSA, Leandro Souza. Colisão de direitos fundamentais: propostas de soluções. Disponível em: <http://conpedi.org/manaus/arquivos/ Anais/Leandro\%20Sousa\%20Bessa.pdf>. Acesso em: 26 fev. 2012.

BORGES, Jose Ademar Campos. O processo do conhecimento humano e as correntes do pensamento jurídico. Disponível em: <http://jus2.uol.com.br/doutrina/texto.asp?id=6751>. Acesso em: 26 fev. 2012.

BRASIL. Constituição (1988). Constituição da República Federativa do Brasil. Brasília, DF: Senado, 1988. Disponível em: <https://www. planalto.gov.br>. Acesso em: 26 fev. 2012.

BUCCI, Maria Paula Dallari. O conceito jurídico de política pública em direito. In: BUCCI, Maria Paula Dallari (Org.). Políticas públicas: reflexões sobre o conceito jurídico. São Paulo: Saraiva, 2006. p. 39-51.

BUCCl, Maria Paula Dallari. Políticas públicas e o direito administrativo. Disponível em: <http://www2.senado.gov.br/bdsf/ bitstream/id/198/4/r133-10.PDF>. Acesso em: 31 jan. 2012.

CAPPELLETTI, Mauro. Juízes legisladores? Tradução de Carlos Alberto Álvaro de Oliveira. Porto Alegre: Fabris, 1999.

CAPPELLETTI, Mauro. Repudiating Montesquieu? The expansion and legitimacy of "Constitutional Justice". Catholic University Law Review, Washington, DC, v. 35, n.1, p.1-32, 1985.

CLAUS, Laurence. Montesquieu's mistakes and the true meaning of separation. Oxford Journal of Legal Studies, v. 25, p. 419, 2005. U San Diego Public Law Research Paper, n. 05-01. Disponível em: <http:// ssrn.com/abstract=558816>. Acesso em: 26 fev. 2012.

CLĖVE, Clèmerson Merlin. Estado constitucional, neoconstitucionalismo e tributação. Disponível em: <http://www. 
cleveadvogados.com.br/arquivos/neoconstitucionalismo-jurisdicaoconstitucional-tributacoa.doc.doc>. Acesso em: 31 jan. 2012.

COMPARATO, Fábio Konder. A afirmação histórica dos direitos humanos. 3. ed. São Paulo: Saraiva, 2003.

COMPARATO, Fábio Konder. Ensaio sobre o juízo de constitucionalidade de políticas públicas. Revista de Informação Legislativa, Brasília, DF, v. 35, n. 138, p. 39-48, abr./jun.1998.

COSTA, Maurício Mesurini da. Controle judicial de políticas públicas: procedimento justificação e responsabilidade. Florianópolis, 2008. 184 f. Dissertação. (Mestrado em Direito) - Centro de Ciências Jurídicas, Universidade Federal de Santa Catarina. Disponível em: <http://www. tede.ufsc.br/teses/PDPC0833-D.pdf>. Acesso em: 26 fev. 2012.

COUTO, Estevão Ferreira. Judicialização da política externa e direitos humanos. Rev. Bras. Polít. Int., Brasília, DF, v. 47, n. 1, jun. 2004. Disponível em: <http://www.scielo.br/scielo.php?script=sci arttext\&pid=S0034-73292004000100007\&Ing=pt\&nrm=iso>. Acesso em: 26 fev. 2012.

DUARTE, ÉcioOtoRamos;POZZOLO, Susanna. Neoconstitucionalismo e positivismo jurídico: as faces da teoria do direito em tempos de interpretação moral da Constituição. São Paulo: Landy, 2006.

DWORKIN, Ronald. Los derechos en serio. Traducción de Marta Guastavino. Barcelona: Ariel, 2002.

DWORKIN, Ronald. Levando os direitos a sério. São Paulo: Martins Fontes, 2002.

DWORKIN, Ronald. Uma questão de princípio. São Paulo: Martins Fontes, 2000.

FACHIN, Melina Girardi. Fundamentos dos direitos humanos: teoria e práxis na cultura da tolerância. Rio de Janeiro: Renovar, 2009.

FINGER, Ana Cláudia. Serviço público: um instrumento de concretização de direitos fundamentais. A\&C Revista de Direito Administrativo e Constitucional, Belo Horizonte, ano 3, n. 12, p. 141-164, abr./jun. 2003. 
FIORAVANTI, Maurizio. Los derechos fundamentales: apuntes de historia de las constituciones. 3. ed. Madrid: Trotta, 2000.

FLORES, Joaquim Herrera. A (re)invenção dos direitos humanos. Florianópolis: Fundação Boitex, 2009.

FREIRE JÚNIOR, Américo Bedê. O controle judicial de políticas públicas. São Paulo: Revista dos Tribunais, 2005.

FREITAS, Juarez. O controle dos atos administrativos e os princípios fundamentais. 4. ed. rev. e ampl. São Paulo: Malheiros, 2009.

GALDINO, Flavio. Introdução à teoria dos custos dos direitos: direitos não nascem em árvores. [S.I.: s.n.], [2000?].

HABERMAS, Jürgen. Direito e democracia: entre faticidade e validade. Tradução Flávio Beno Siebeneichler. 2. ed. Rio de Janeiro: Tempo Brasileiro, 2003.

HAMILTON, Alexander; JAY, John; MADISON, James. O federalista. 2. ed. Campinas: Russell, 2005.

HIRSCHL, Ran. Towards juristocracy: the origens and consequences of the new constitucionalism. Massachusetts: Harvard University Press, 2004.

HOLMES, Stephen; SUNSTEIN, Cass R. The cost of rights: why liberty depends on taxes. New York: W.W. Norton, 2000.

KELSEN, Hans. Teoria pura do direito. 6. ed. São Paulo: Martins Fontes, 1998.

KRELL, Andreas Joachim. Direitos sociais e controle judicial no Brasil e na Alemanha: os (des)caminhos de um direito constitucional comparado. Porto Alegre: Fabris, 2002.

MADISON, James. The particular structure of the new government and the distribution of power among its different parts. New York Packet, New York, Jan. 30, 1788. Original publicado em The Federalist, n. 47. Disponível em: <http://www.constitution.org/fed/federa47.htm>. Acesso em: 26 fev. 2012. 
MADISON, James. The structure of the government must furnish the proper checks and balances between the different departments. Independent Journal, New York, Feb. 6, 1788. Disponível em: <http:// www.constitution.org/fed/federa51.htm>. Acesso em: 26 fev. 2012. Original publicado em The Federalist, n. 51.

MADISON, James. These departments should not be so far separated as to have no constitutional control over each other. The Federalist, $\mathrm{n}$. 48. New York Packet, New York, Feb. 1, 1788. Original publicado em The Federalist, n. 48. Disponível em: <http://www.constitution.org/fed/ federa48.htm>. Acesso em: 26 fev. 2012.

MANCUSO, Rodolfo de Camargo. A ação civil pública como instrumento de controle judicial das chamadas políticas públicas. In: MILARÉ, Edis (Coord.). Ação civil pública: Lei n. 7.347 - 15 anos. São Paulo: Revista dos Tribunais, 2001. p. 753-798.

MÂNICA, Fernando Borges. Teoria da reserva do possível: direitos fundamentais a prestações e a intervenção do poder judiciário na implementação de políticas públicas. Cadernos da Escola de Direito e Relações Internacionais da UniBrasil, Curitiba, v. 8, n. 8, p. 89-104, jan./jul. 2008.

MASSA-ARZABE, Patrícia Helena. Dimensão jurídica das políticas públicas. In: $\mathrm{BUCCl}$, Maria Paula Dallari (Org.). Políticas públicas: reflexões sobre o conceito jurídico. São Paulo: Saraiva, 2006. p. 51-74.

MEDAUAR, Odete. Direito administrativo moderno. 10. ed. rev. atual. ampl. São Paulo: Revista dos Tribunais, 2006.

MELO, Marcus André. O viés majoritário na política comparada: responsabilização, desenho institucional e qualidade democrática. Disponível em: <http://www.scielo.br/pdf/rbcsoc/v22n63/a03v2263.pdf>. Acesso em: 26 fev. 2012.

MONTESQUIEU, Charles Louis de Secondat. Do espírito das leis (1748). São Paulo: Abril Cultural, 1979.

NATEL, Maurício da Luz. O suprimento judicial da omissão legislativa: possibilidade ante o atual conteúdo do princípio da separação dos 
poderes. Curitiba, 2007. 166 f. Dissertação (Mestrado em Direito) - Setor de Ciências Jurídicas da Universidade Federal do Paraná. Disponível em: $\quad<$ http://dspace.c3sl.ufpr.br/dspace/bitstream/1884/8078/1/ Disserta\%c3\%a7\%c3\%a3o\%20Mauricio\%20Natel.pdf>. Acesso em: 26 fev. 2012.

NOVAIS, Jorge Reis. Direitos fundamentais: trunfos contra a maioria. Coimbra: Almedina, 2006.

NOVAIS, Jorge Reis. Direitos sociais: teoria dos direitos sociais enquanto direitos fundamentais. Coimbra: Coimbra Ed., 2010.

OLIVEIRA, Gustavo Henrique Justino de. Administração pública democrática e efetivação de direitos fundamentais. In: CLÈVE, Clèmerson Merlin; SARLET, Ingo Wolfgang; PAGLIARINI, Alexandre Coutinho (Coord.). Direitos humanos e democracia. Rio de Janeiro: Forense, 2007. p. 307-329.

OMMATI, Ricardo Emilio Medauar. Controle da discricionariedade. Porto Alegre: Fabris, 2004.

PEREIRA JÚNIOR, Jessé Torres. Controle judicial da administração pública: da legalidade estrita à lógica do razoável. 2. ed. Belo Horizonte: Fórum. 2006.

PÉREZ LUÑO, António Enrique. Los derechos fundamentales. Madrid: Tecnos, 2004.

PIOVESAN, Flávia. Proteção internacional dos direitos econômicos, sociais e culturais. In: SARLET, Ingo Wolfgang (Org.). Direitos fundamentais sociais: estudos de direito constitucional, internacional e comparado. Rio de Janeiro: Renovar, 2003. p. 233-261.

PRADO, Safira Orçatto Merelles do. O controle judicial dos serviços públicossobaperspectivade concretização dedireitos fundamentais. Curitiba, 2007. 171 f. Dissertação (Mestrado em Direito). - Setor de Ciências Jurídicas, Universidade Federal do Paraná. Disponível em: <http://dspace.c3sl.ufpr.br/dspace/bitstream/1884/11566/1/controle\%20 judicial\%20-\%20safira\%20prado.pdf>. Acesso em: 26 fev. 2012. 
PUCCINELLI JÚNIOR, André. A omissão legislativa inconstitucional e a responsabilidade do Estado legislador. São Paulo: Saraiva, 2007.

SANTOS, Marília Lourido dos. Políticas públicas (econômicas) e controle. Disponível em: <http://www2.senado.gov.br/bdsf/bitstream/ id/862/4/R158-17.pdf>. Acesso em: 26 fev. 2012.

SARLET, Ingo Wolfgang. A eficácia dos direitos fundamentais: uma teoria geral dos direitos fundamentais na perspectiva constitucional. 8. ed. rev. atual e ampl. Porto Alegre: Livraria do Advogado, 2007.

SCHIER, Adriana da Costa Ricardo. Regime jurídico do serviço público: garantia fundamental do cidadão e proibição do retrocesso social. Curitiba, 2009. 214 f. Tese (Doutorado em Direito) - Setor de Ciências Jurídicas, Universidade Federal do Paraná. Disponível em: <http://dspace.c3sl.ufpr.br/dspace/bitstream/1884/21460/1/Binder1. pdf>. Acesso em: 26 fev. 2012.

SCHIER, Paulo Ricardo. Direito constitucional: anotações nucleares. Curitiba: Juruá, 2003.

SILVA, José Afonso da. Aplicabilidade das normas constitucionais. 7. ed. São Paulo: Malheiros, 2009.

SOUZA NETO, Cláudio Pereira de. Teoria da constituição, democracia e igualdade. In: SOUZA NETO, Cláudio Pereira de et al. Teoria da constituição: estudos sobre o lugar da política no direito constitucional. Rio de Janeiro: Lumen Juris, 2003. p.1-73.

SUNSTEIN, Cass R. The second bill of rights: FDR's unfinished revolution and why we need it more than ever. New York: Basic Books, 2004.

TAMER, Sergio Victor. Atos políticos e direitos sociais nas democracias: um estudo sobre o controle dos atos políticos e a garantia judicial dos direitos sociais. Porto Alegre: Fabris, 2005.

VALLE, Vanice Regina Lírio do. Políticas públicas, direitos fundamentais e controle judicial. Rio de Janeiro: Fórum, 2009. 
WOOD, John. Separation of powers before and after the seventeenth amendment. Disponível em: <http://ssrn.com/abstract=1909009>. Acesso em: 15 ago. 2011.

Recebido em: 00/11/13

Aprovado em: 00/12/13 